\title{
Preoperative dexamethasone reduces postoperative pain, nausea and vomiting following mastectomy for breast cancer
}

\author{
Jorge Gómez-Hernández , Alba Lorena Orozco-Alatorre', Marisela Domínguez-Contreras', \\ Antonio Oceguera-Villanueva', Salvador Gómez-Romo ${ }^{1}$, Andrea Socorro Alvarez Villaseñor ${ }^{2}$, \\ Clotilde Fuentes-Orozco ${ }^{2}$, Alejandro González-Ojeda²*
}

\begin{abstract}
Background: Dexamethasone has been reported to reduce postoperative symptoms after different surgical procedures. We evaluated the efficacy of preoperative dexamethasone in ameliorating postoperative nausea and vomiting (PONV), and pain after mastectomy.

Methods: In this prospective, double-blind, placebo-controlled study, 70 patients scheduled for mastectomy with axillary lymph node dissection were analyzed after randomization to treatment with $8 \mathrm{mg}$ intravenous dexamethasone $(n=35)$ or placebo $(n=35)$. All patients underwent standardized procedures for general anesthesia and surgery. Episodes of PONV and pain score were recorded on a visual analogue scale. Analgesic and antiemetic requirements were also recorded.

Results: Demographic and medical variables were similar between groups. The incidence of PONV was lower in the dexamethasone group at the early postoperative evaluation $(28.6 \%$ vs. $60 \% ; p=0.02)$ and at $6 \mathrm{~h}(17.2 \% \mathrm{vs}$. $45.8 \% ; p=0.03$ ). More patients in the placebo group required additional antiemetic medication ( $21 \mathrm{vs} .8 ; p=0.01$ ). Dexamethasone treatment significantly reduced postoperative pain just after surgery (VAS score, $4.54 \pm 1.55$ vs. 5.83 $\pm 2.00 ; p=0.004)$, at $6 \mathrm{~h}(3.03 \pm 1.20$ vs. $4.17 \pm 1.24 ; p<0.0005)$ and at $12 \mathrm{~h}(2.09 \pm 0.85$ vs. $2.54 \pm 0.98 ; p=0.04)$. Analgesics were required in more patients of the control group (21 vs. 10; $p=0.008$ ). There were no adverse events, morbidity or mortality.
\end{abstract}

Conclusions: Preoperative intravenous dexamethasone $(8 \mathrm{mg})$ can significantly reduce the incidence of PONV and pain in patients undergoing mastectomy with axillary dissection for breast cancer.

Trial registration number: NCT01116713

\section{Background}

Breast cancer is the most frequent malignant neoplasm worldwide. In emerging countries such as Mexico, there has been an increase in its frequency and mortality $[1,2]$ and it is the second most frequent neoplasm after cervical carcinoma. Between 25,000 and 30,000 new cases are diagnosed annually. Unfortunately, only a few women have regular mammography screening so the proportion

\footnotetext{
* Correspondence: avygail5@yahoo.com.mx

${ }^{2}$ Research Unit in Clinical Epidemiology, Specialties Hospital, Western Medical Center. Mexican Institute of Social Security. Avenida Belisario Domínguez 1000, Colonia Independencia. Postal code 44340, Guadalajara, Jalisco. México Full list of author information is available at the end of the article
}

of patients with locally advanced disease at diagnosis is high. In 2003, only $5-10 \%$ of newly diagnosed cases in Mexico were clinical stages 0 or I [2]. Surgical resection with axillary lymph node dissection constitutes the treatment of choice associated with neoadjuvant therapy and postoperative chemotherapy and/or radiation therapy.

Postoperative nausea and vomiting (PONV) are the most common complications after anesthesia and surgery $[3,4]$. Women undergoing mastectomy with axillary dissection are at a particularly high risk for the development of PONV and an incidence of $60-80 \%$ in patients receiving no antiemetic has been reported [5-7].

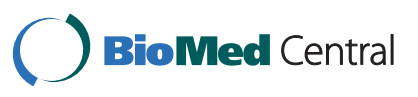


Emetic episodes predispose to aspiration of gastric contents, wound dehiscence, psychological distress, and delayed recovery and discharge times [3]. These justify the use of prophylactic antiemetics in women scheduled for mastectomy. Most of the currently used antiemetics, including antihistamines, butyrophenones and dopamine receptor antagonists have been reported to cause occasional undesirable adverse effects, such as excessive sedation, hypotension, dry mouth, dysphoria, hallucinations and extrapyramidal signs [3]. Antiserotonins (e.g., ondansetron) are available for the prevention and treatment of PONV in patients undergoing various types of surgery [4]. However, the use of prophylactic antiemetic therapy with antiserotonins has been criticized for being too expensive $[8,9]$.

Dexamethasone was first reported to be an effective antiemetic regimen in patients receiving cancer chemotherapy [10]. Holte et al. [11] have reviewed the available randomized trials (1996-2001) regarding perioperative single-dose steroid administration and found that dexamethasone had antiemetic and analgesic effects in various types of operations. Wattwil et al. [12] showed that dexamethasone at $4 \mathrm{mg}$ was effective for the prevention of PONV following breast surgery but they could not demonstrate any difference in postoperative pain.

The purpose of this study was to evaluate the efficacy of dexamethasone treatment for reducing pain and PONV as well as analgesic and antiemetic requirements in women undergoing general anesthesia for mastectomy with axillary lymph node dissection.

\section{Methods \\ Patients}

Between June and August 2009, 70 patients undergoing mastectomy with axillary dissection were studied in a prospective, randomized, double-blind clinical trial. Patients were randomized to receive intravenous dexamethasone $(8 \mathrm{mg})$ or homologated placebo 60 minutes before skin incision, using an equal number of blinded envelopes. Patients of American Society of Anesthesiologists classes III and IV were excluded. Further exclusion criteria were age more than 80 years; pregnancy; active menstruation; treatment with steroids; severe diabetes mellitus (serum HbA1c > 8\%); use of opioids, sedatives or any kind of analgesics less than one week before mastectomy, or a history of alcohol or drug abuse. Patients with any history of motion sickness and/or previous PONV after any surgical procedure were excluded. All patients were admitted to the hospital one day before the operation and were followed from hospital admission until 30 days after the surgical procedure to detect any medical or surgical morbidity.

\section{Anesthesia and surgery}

All patients underwent a standardized general anesthesia procedure and none of them received any preanesthetic medication. Induction used intravenous propofol ( $2 \mathrm{mg} / \mathrm{kg}$ body weight) and fentanyl $(3-5 \mu \mathrm{g} / \mathrm{kg})$. Vecuronium bromide $(0.1 \mathrm{mg} / \mathrm{kg})$ was used to facilitate tracheal intubation. Anesthesia was maintained with $2-3 \%$ sevoflurane and $66 \%$ nitrous oxide in oxygen. Ventilation was controlled mechanically and maintained constant throughout surgery using an anesthetic and respiratory gas analyzer for monitoring.

All patients were monitored with indirect determinations of arterial pressure and heart rate using standard techniques, as well as the expired $\mathrm{CO}_{2}$ content and oxygen blood saturation. Afterwards, all patients were extubated and transferred to the immediate postsurgical care unit with cardiovascular and oxygen monitoring.

\section{Surgical procedures}

All patients were treated according to the preoperative clinical stage with radical mastectomy or breast conservative surgery with lymph node axillary dissection by the same surgical team. In all patients, closed suction drains were placed in the region subjected to surgery and were removed during the following days. Chemotherapy and/or radiotherapy were administered 3-4 weeks after uncomplicated surgical resections.

\section{Analgesia and antiemetic therapies}

Pain was assessed immediately on return to the recovery room and at 6, 12 and $24 \mathrm{~h}$ after the operation using a visual analogue scale $(\mathrm{VAS} ; 0=$ no pain to $10=$ most severe pain). Analgesia was given as intravenous sodium ketorolac (30 mg every 8 hours) and intravenous tramadol infusion $(50 \mathrm{mg}$ ) was used as a backup analgesic medication. The incidence of PONV was recorded immediately on return to the recovery room and at 6 , 12 and $24 \mathrm{~h}$ after the operation, using a three point ordinal scale $(0=$ none, $1=$ nausea, $2=$ retching, $3=$ vomiting). Nausea was defined as a subjectively unpleasant sensation associated with awareness of the urge to vomit, retching was defined as the labored, spasmodic, rhythmic contraction of the respiratory muscles without the expulsion of gastric contents, and vomiting was defined as the forceful expulsion of gastric contents from the mouth. Intravenous ondasetron (4-8 $\mathrm{mg}$ ) was given for antiemetic treatment on demand.

\section{Data collection and statistical analysis}

Postoperative complications were recorded during hospitalization and the patients were followed up to 30 days after discharge. Additional data collected included patient age, body mass index (BMI), any history of 
smoking and neoadjuvant chemotherapy, anesthesia and operation time and the frequency of use of analgesic and antiemetic drugs. These parameters were summed and compared between the dexamethasone and placebo groups. The study endpoints were postoperative nausea and vomiting, and pain measured by the VAS and the need for additional analgesic and antiemetic drugs.

The sample size was predetermined. We expected a 35 percent point difference in the incidence of nausea and vomiting between groups favoring dexamethasone use. The $\alpha$ error was set at 0.05 and $\beta$ error at $0.20 ; n=35$ patients for each group was considered adequate, according to a power analysis. Results are expressed as percentages and as the mean \pm standard deviation (SD). Student's $t$ test, and Fisher's Exact Test were used for the analysis of quantitative and qualitative data, respectively. Two-sided tests were used to declare statistical significance at $p<0.05$.

\section{Ethical considerations}

The study was conducted according to the principles of the Declaration of Helsinki of 1989 and the Mexican Health Guidelines. The Ethical and Research Committees of the Oncologic Institute of Jalisco, Mexico approved all protocols. Full, written informed consent was obtained from all patients before their inclusion in the study.

\section{Results}

There were no significant differences between the two groups with regard to mean age, weight, height, BMI, neoadjuvant chemotherapy, type of surgical procedure, length of surgical procedures, length of anesthesia or operative bleeding (Table 1). Figure 1 shows the median VAS values for pain. Dexamethasone significantly reduced postoperative pain just after surgery (VAS score, $4.54 \pm 1.55$ vs. $5.83 \pm 2.00 ; p=0.004), 6 \mathrm{~h}$ after the operation (VAS score, $3.03 \pm 1.20$ vs. $4.17 \pm 1.24$; $p<0.0005$ ) and $12 \mathrm{~h}$ after the breast surgery (VAS score, $2.09 \pm 0.85$ vs. $2.54 \pm 0.98 ; p=0.04)$. No difference was observed $24 \mathrm{~h}$ after the operation $(1.23 \pm 0.42$ $v s .1 .43 \pm 0.55 ; p=0.09$ ). Analgesics were required in more patients of the control group than in the dexamethasone group (21 vs. $10 ; p=0.008)$. The mean dose of intravenous tramadol was lower in the study group (36.01 \pm 12.62 vs. $55.74 \pm 27.36 ; p=0.03$ ).

The incidence of PONV is described in Table 2. There were significant differences between the two groups in terms of the early postoperative evaluation in the recovery room and at $6 \mathrm{~h}$, favoring the dexamethasone group. More patients in the placebo group required the administration of additional antiemetics (21 vs. 8; $p=0.01$ ); the mean dose of ondansetron was $7.05 \pm 2.80 \mathrm{mg}$ in the control group and $4.50 \pm 1.41 \mathrm{mg}$ in the study group $(p=0.02)$.

The hospital stay was 1-3 days. No morbidity was observed during the follow up period. Drains were removed when the fluid output was less than $50 \mathrm{ml} / 24$ h. One patient in the control group developed a generalized rash before the skin incision was started. The adverse event was treated with intravenous antihistaminic and hydrocortisone with complete resolution.

Table 1 Baseline characteristics of the patients in the study and the placebo groups

\begin{tabular}{|c|c|c|}
\hline & $\begin{array}{l}\text { Placebo group } \\
(\mathrm{n}=35)\end{array}$ & Dexamethasone group $(n=35)$ \\
\hline Age (years) ${ }^{a}$ & $49.89 \pm 10.58$ & $50.11 \pm 12.37$ \\
\hline Weight $(\mathrm{kg})^{\mathrm{a}}$ & $67.94 \pm 9.91$ & $69.52 \pm 13.63$ \\
\hline Height $(\mathrm{cm})^{\mathrm{a}}$ & $158.14 \pm 6.33$ & $157.31 \pm 6.57$ \\
\hline Body mass index ${ }^{a}$ & $27.20 \pm 4.29$ & $28.20 \pm 6.38$ \\
\hline Normal weight 20-25 (\%) & $11(31.4 \%)$ & $12(34.3 \%)$ \\
\hline Overweight 25.1-29.9 (\%) & $15(42.9 \%)$ & $14(40 \%)$ \\
\hline Obesity grade I 30-34.9 (\%) & 7 (20\%) & $5(14.3 \%)$ \\
\hline Obesity grade I| 35-39.9 (\%) & $2(5.7 \%)$ & $2(5.7 \%)$ \\
\hline Obesity grade III >40 (\%) & 0 & $2(5.7 \%)$ \\
\hline Smoking (\%) & $2(5.7 \%)$ & $4(11.4 \%)$ \\
\hline Neoadjuvant chemotherapy (\%) & $13(37.1 \%)$ & $15(42.8 \%)$ \\
\hline \multicolumn{3}{|l|}{ Surgical procedure } \\
\hline Radical mastectomy + axillary dissection (\%) & $32(91.4 \%)$ & $34(97.1 \%)$ \\
\hline Quadrantectomy + axillary dissection (\%) & $3(8.6 \%)$ & $1(2.9 \%)$ \\
\hline Surgery time $(\min )^{a}$ & $119.42 \pm 26.97$ & $120.54 \pm 30.34$ \\
\hline Length of anesthesia $(\mathrm{min})^{\mathrm{a}}$ & $140.71 \pm 26.76$ & $139.60 \pm 34.56$ \\
\hline Bleeding $(\mathrm{ml})^{\mathrm{a}}$ & $165.85 \pm 61.10$ & $156.85 \pm 60.11$ \\
\hline
\end{tabular}

${ }^{a}$ Values are expressed as the mean \pm standard deviation. 


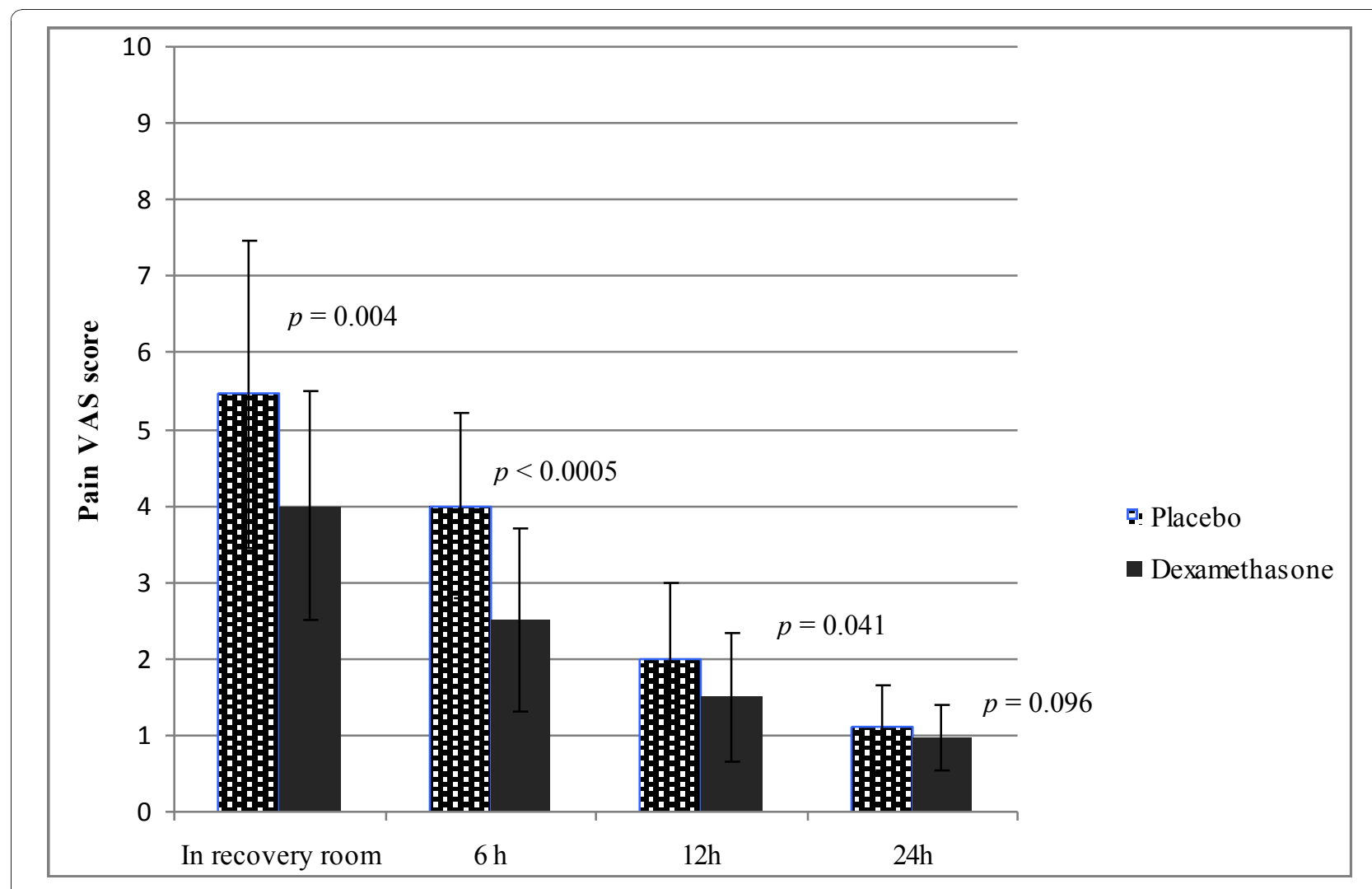

Figure 1 Pain VAS score of patients in the control and study groups.

This case was excluded and substituted with a new candidate. There was no mortality.

\section{Discussion}

In this randomized, double-blind, placebo-controlled study, preoperative dexamethasone $(8 \mathrm{mg})$ significantly reduced the incidence of pain, PONV and analgesic and antiemetic requirements after breast surgery for cancer.
PONV is an unpleasant, distressing and exhausting complication for patients. It can prolong recovery time, delay patient discharge and increase hospital costs [13]. The etiology of PONV after breast surgery is not entirely clear. Factors affecting PONV after breast surgery are those related to the patients, those related to the surgical procedure and the anesthetic technique and the postoperative care [14]. Risk-scoring systems have

Table 2 Incidence of PONV in the dexamethasone and placebo groups

\begin{tabular}{|c|c|c|c|}
\hline & Placebo group $(n=35)$ & Dexamethasone group $(n=35)$ & $P$ \\
\hline \multicolumn{4}{|l|}{ In recovery room: } \\
\hline$\triangleright$ PONV & $21(60 \%)$ & $10(28.6 \%)$ & 0.02 \\
\hline$\triangleright$ Asymptomatic & $14(40 \%)$ & $25(71.4 \%)$ & \\
\hline \multicolumn{4}{|l|}{$6 \mathrm{~h}$ after surgery: } \\
\hline$\triangleright$ PONV & $16(45.8 \%)$ & $6(17.2 \%)$ & 0.03 \\
\hline$\triangleright$ Asymptomatic & $19(54.2 \%)$ & $29(82.8 \%)$ & \\
\hline \multicolumn{4}{|l|}{$12 \mathrm{~h}$ after surgery: } \\
\hline$\triangleright$ PONV & $6(11.2 \%)$ & $4(11.5 \%)$ & 0.35 \\
\hline$\triangleright$ Asymptomatic & $29(82.8 \%)$ & $31(88.5 \%)$ & \\
\hline \multicolumn{4}{|l|}{24 h after surgery: } \\
\hline$\triangleright$ PONV & $5(14.3 \%)$ & $1(2.9 \%)$ & 0.23 \\
\hline$\triangleright$ Asymptomatic & $30(85.7 \%)$ & 34 (97.1\%) & \\
\hline
\end{tabular}

PONV, postoperative nausea and vomiting.

$p$ values calculated using two-sided Fisher's Exact Test. 
been proposed based on logistic regression modeling to select patients for prophylaxis against PONV $[15,16]$. Complicated formulations were simplified establishing four predictor factors: a) female sex; b) a history of motion sickness and/or PONV; c) absence of a smoking habit and d) any use of opioids [17]. If none, one, two, three or four of these factors were present, the incidence of PONV was $10 \%, 23 \%, 39 \%, 61 \%$ and $79 \%$ respectively [17]. Breast surgery inherently caters to high-risk patients and being female was an independent predictor for PONV in multivariate analysis $[15,16]$. In our study patients with history of motion sickness and/or PONV were not included and only a few of our patients were active smokers. The first condition lowers the threshold for vomiting [18] and smoking provides some protection against it [3]. The length of the surgical procedure also increases the risk of PONV. As established by Sinclair et al. [16], each $30 \mathrm{~min}$ increase in the duration of surgery increases the incidence of PONV by $60 \%$. Anesthetic-related factors have a strong influence on the incidence of PONV because the use of opioids as premedications or to maintain anesthesia stimulates central nervous system (CNS) opioid receptors [19]. Nitrous oxide causes PONV by stimulating the CNS with catecholamine release and changes in middle-air pressure with subsequent stimulation of the vestibular system and elevation of abdominal pressure as a consequence of the exchange of nitrous oxide and nitrogen in gas introduced into the gastrointestinal tract during mask ventilation [20-24]. The use of propofol for maintaining anesthesia has a positive effect on reducing PONV [25]. Postoperatively, the administration of opioids might contribute to these episodes [26].

Since the original description of dexamethasone as an effective antiemetic drug [10], studies have reported it to be effective for the prevention of nausea and vomiting after different surgical procedures. The biological action of a glucocorticoid begins 1-2 $\mathrm{h}$ after administration [27]. The antiemetic mechanism of dexamethasone is not known. However, central inhibition of prostaglandin synthesis, inhibition of endogenous opioid release and changes in the permeability of the blood-brain barrier to serum proteins have been suggested $[27,28]$. The analgesic effects of glucocorticoids are mainly provided through the peripheral inhibition of phospholipase, thereby decreasing the products of the cyclooxygenase and lipoxygenase pathways in the inflammatory response [29].

In this trial, a variety of risk factors were present in both groups of patients. This included being female, nonsmoking, receiving neoadjuvant chemotherapy, undergoing an operative procedure and anesthesia, the presence of postoperative pain and the use of opioids. All of these factors are considered to affect the incidence of PONV; however, they were well balanced between the placebo and dexamethasone treatment groups. Therefore, the difference in the rate of patients experiencing PONV among the groups can be attributed to the use of dexamethasone.

Our results are similar to those reported by Fujii and Nakayama [30]. They designed a randomized clinical trial with 90 patients submitted to breast surgery (24\% of them treated without axillary lymph node dissection). They divided the patients into three groups of 30. Patients received intravenous dexamethasone at doses of 4 or $8 \mathrm{mg}$ preoperatively and the control group received placebo. They evaluated the incidence of PONV and analgesic requirements until $24 \mathrm{~h}$ after the surgical procedure. The incidence of PONV was $67 \%$ in the placebo group versus $33 \%$ and $27 \%$ in the 4 $\mathrm{mg}$ and $8 \mathrm{mg}$ dexamethasone groups $(p=0.01$ and 0.002 , respectively). The need for rectally administered indomethacin for relieving intolerable pain was less in patients who had received $8 \mathrm{mg}$ dexamethasone than in those who received placebo $(p=0.001)$ or dexamethasone at $4 \mathrm{mg}(p=0.034)$. No difference in analgesic requirement was found between the $4 \mathrm{mg}$ dexamethasone and placebo groups $(p=0.18)$. They concluded that dexamethasone at $8 \mathrm{mg}$ effectively decreased PONV and analgesic requirements in women undergoing general anesthesia.

\section{Conclusions}

Our results suggest that preoperative dexamethasone at $8 \mathrm{mg}$ ameliorates nausea, vomiting, pain and reduces the analgesic and antiemetic requirements of women after breast surgery for cancer without apparent side effects. It appears to be a valuable treatment for preventing such adverse postoperative symptoms.

\section{Acknowledgements and funding}

We thank Agustina Elena Vilchis-Guizar MD, for her assistance in preparing the final manuscript. This work was supported with financial resources of the participant institutions and in part by a grant of the Health Research Found of the Mexican Institute of Social Security (IMSS, Mexico, D.F.).

\section{Author details}

${ }^{1}$ Breast Tumor Clinic. Oncologic Institute of Jalisco, Health Secretary. Calle Coronel Calderon 715, Colonia El Retiro. Postal code 44280, Guadalajara, Jalisco. México. ${ }^{2}$ Research Unit in Clinical Epidemiology, Specialties Hospital, Western Medical Center. Mexican Institute of Social Security. Avenida Belisario Domínguez 1000, Colonia Independencia. Postal code 44340, Guadalajara, Jalisco. México.

\section{Authors' contributions}

ASAV, CFO and AGO were responsible for conceiving and designing the study as well as analyzing and interpreting the data and writing the different stages of the manuscript. ALOA and MDC were responsible for coordination of the subject recruitment for the study and participated in data interpretation. JGH, AOV and SGR were responsible to treat surgically the study patients.

All authors read and approved the final manuscript. 


\section{Authors' information}

Breast Tumor Clinic. Oncologic Institute of Jalisco, Health Secretary. Calle Coronel Calderon 715, Colonia El Retiro. Postal code 44280, Guadalajara, Jalisco. Mexico.

Research Unit in Clinical Epidemiology, Specialties Hospital, Western Medical Center. Mexican Institute of Social Security. Avenida Belisario Dominguez 1000, Colonia Independencia. Postal code 44340, Guadalajara, Jalisco. Mexico.

\section{Competing interests}

The authors declare that they have no competing interests.

Received: 5 May 2010 Accepted: 23 December 2010

Published: 23 December 2010

\section{References}

1. Jemal A, Siegel R, Ward E, Hao Y, Xu J, Murray T, Thun MJ: Cancer statistics. CA Cancer J Clin 2008, 58:71-96.

2. DGE/SSA: Grupos etáreos: Registro Histopatológico de Neoplasias en México (RHPNM). Mexico City 2003, CD-ROM.

3. Watcha MF, White PF: Postoperative nausea and vomiting: its etiology, treatment, and prevention. Anesthesiology 1992, 77:162-184.

4. Kovac AL: Prevention and treatment of postoperative nausea and vomiting. Drugs 2000, 59:213-243.

5. Oddby-Muhrbeck E, Jakobsson J, Andersson L, Askergren J: Postoperative nausea and vomiting: a comparison between intravenous and inhalation anaesthesia in breast surgery. Acta Anaesthesiol Scand 1994, 38:52-56.

6. Sadhasivam S, Saxena A, Kathirvel S, Kannan TR, Trikha A, Mohan V: The safety and efficacy of prophylactic ondansetron in patients undergoing modified radical mastectomy. Anesth Analg 1999, 89:1340-1345.

7. Hammas B, Thorn SE, Wattwil M: Superior prolonged antiemetic prophylaxis with a four-drug multimodal regimen-comparison with propofol or placebo. Acta Anaesthesiol Scand 2002, 46:232-237.

8. White PF, Watcha MF: Are new drugs cost-effective for patients undergoing ambulatory surgery? Anesthesiology 1993, 78:2-5.

9. Lerman J: Are antiemetics cost-effective for children? Can J Anaesth 1995, 42:263-266.

10. Aapro MS, Alberts DS: Dexamethasone as an antiemetic in patients treated with cisplatin. N Engl J Med 1981, 305:520.

11. Holte K, Kehlet H: Perioperative single-dose glucocorticoid administration: pathophysiologic effects and clinical implications. J Am Coll Surg 2002, 195:694-712.

12. Wattwil M, Thorn SE, Lovqvist A, Wattwil L, Gupta A, Liljegren G Dexamethasone is as effective as ondansetron for the prevention of postoperative nausea and vomiting following breast surgery. Acta Anaesthesiol Scand 2003, 47:823-827.

13. Koivaranta M, Laara E, Snare L, Alahuhta S: A survey of postoperative nausea and vomiting. Anesthesia 1997, 52:443-449.

14. Fujii Y: Prophylaxis of postoperative nausea and vomiting in patients scheduled for breast surgery. Clin Drug Invest 2006, 26:427-437.

15. Apfel CC, Greim CA, Haubitz I, Goepfert C, Usadel J, Sefrin P, Roewer N: A risk score to predict the probability of postoperative vomiting in adults. Acta Anaesthesiol Scand 1998, 42:495-501.

16. Sinclair DR, Chung F, Mezei G: Can postoperative nausea and vomiting be predicted? Anesthesiology 1999, 91:109-118.

17. Apfel CC, Laara E, Koivuranta M, Greim CA, Roewer N: A simplified risk score for predicting postoperative nausea and vomiting: conclusion from cross-validations between two centers. Anesthesiology 1999, 91:693-700.

18. Smessaert A, Schehr CA, Artusio JF Jr: Nausea and vomiting in the immediate postoperative period. JAMA 1959, 170:2072-2076.

19. Jenkins JC, Lahay D: Central mechanisms of vomiting related to catecholamine response: anaesthetic implication. Can Anaesth Soc J 1971, 18:434-441.

20. Perreault L, Normandin N, Plamondon L, Blain R, Rousseau P, Girard M, Foget G: Middle ear pressure variations during nitrous oxide-oxygen anesthesia. Can Anaesth Soc J 1982, 29:428-434.

21. Egar El II, Saidman L: Hazards of nitrous oxide anesthesia in bowel obstruction and pneumothorax. Anesthesiology 1965, 26:61-66.

22. Hartung J: Twenty-four of twenty-seven studies show a greater incidence of emesis with nitrous oxide than with alternative anesthetics. Anesth Analg 1996, 83:114-116.
23. Vanacker BF: The impact of nitrous oxide on postoperative nausea and vomiting after desflurane anesthesia for breast surgery. Acta Anaesth Belg 1999, 50:77-81.

24. Fernández-Guisasola J, Gómez-Arnau Jl, Cabrera Y, del Valle SG: Association between nitrous oxide and the incidence of postoperative nausea and vomiting in adults: a systematic review and meta-analysis. Anaesthesia 2010, 65:379-387.

25. Sneyd JR, Carr A, Byrom WD, Bilski AJ: A meta-analysis of nausea and vomiting following maintenance of anaesthesia with propofol or inhalational agents. Eur J Anaesthesiol 1998, 15:433-445.

26. Apfel CC, Korttila K, Abdalla M, Kerger H, Turan A, Vedder I, Zernak C, Danner K, Jokela R, Pocock SJ, Trenkler S, Kredel M, Biedler A, Sessler DI, Roewer N: A factorial trial of six interventions for the prevention of postoperative nausea and vomiting. N Engl J Med 2004, 350:2441-2451.

27. Holte K, Kehlet $\mathrm{H}$ : Perioperative single-dose glucocorticoid administration: pathophysiologic effects and clinical implications. J Am Coll Surg 2000, 195:694-712.

28. Livrea P, Trojano M, Simone IL, Zimatore GB, Logroscino GC, Pisicchio L, Lojacono G, Colella R, Ceci A: Acute changes in blood CSF barrier permselectivity to serum protein after intrathecal methotrexate and CNS irradiation. J Neurol 1985, 231:336-339.

29. Sapolsky RM, Romero LM, Munck AU: How do glucocorticoids influence stress responses? Integrating permissive, suppressive, stimulatory, and preparative actions. Endocr Rev 2000, 21:55-89.

30. Fujii Y, Nakayama M: Reduction of postoperative nausea and vomiting and analgesic requirement with dexamethasone in women undergoing general anesthesia for mastectomy. Breast J 2007, 13:564-567.

\section{Pre-publication history}

The pre-publication history for this paper can be accessed here: http://www.biomedcentral.com/1471-2407/10/692/prepub

\section{doi:10.1186/1471-2407-10-692}

Cite this article as: Gómez-Hernández et al:: Preoperative dexamethasone reduces postoperative pain, nausea and vomiting following mastectomy for breast cancer. BMC Cancer 2010 10:692.

\section{Submit your next manuscript to BioMed Central and take full advantage of:}

- Convenient online submission

- Thorough peer review

- No space constraints or color figure charges

- Immediate publication on acceptance

- Inclusion in PubMed, CAS, Scopus and Google Scholar

- Research which is freely available for redistribution

Submit your manuscript at www.biomedcentral.com/submit
C Biomed Central 